Supporting Information for

\title{
An Efficient Pathway for Preparing Hollow Particles: Site-Specific Crosslinking of Spherical Polymer Particles with Photo-Responsive Groups That Play a Dual Role in Shell Crosslinking and Core Shielding
}

Yukiya Kitayama, Kazuki Yoshikawa, Toshifumi Takeuchi*

Graduate School of Engineering, Kobe University, 1-1, Rokkodai-cho, Nada-ku, Kobe 657-8501, Japan
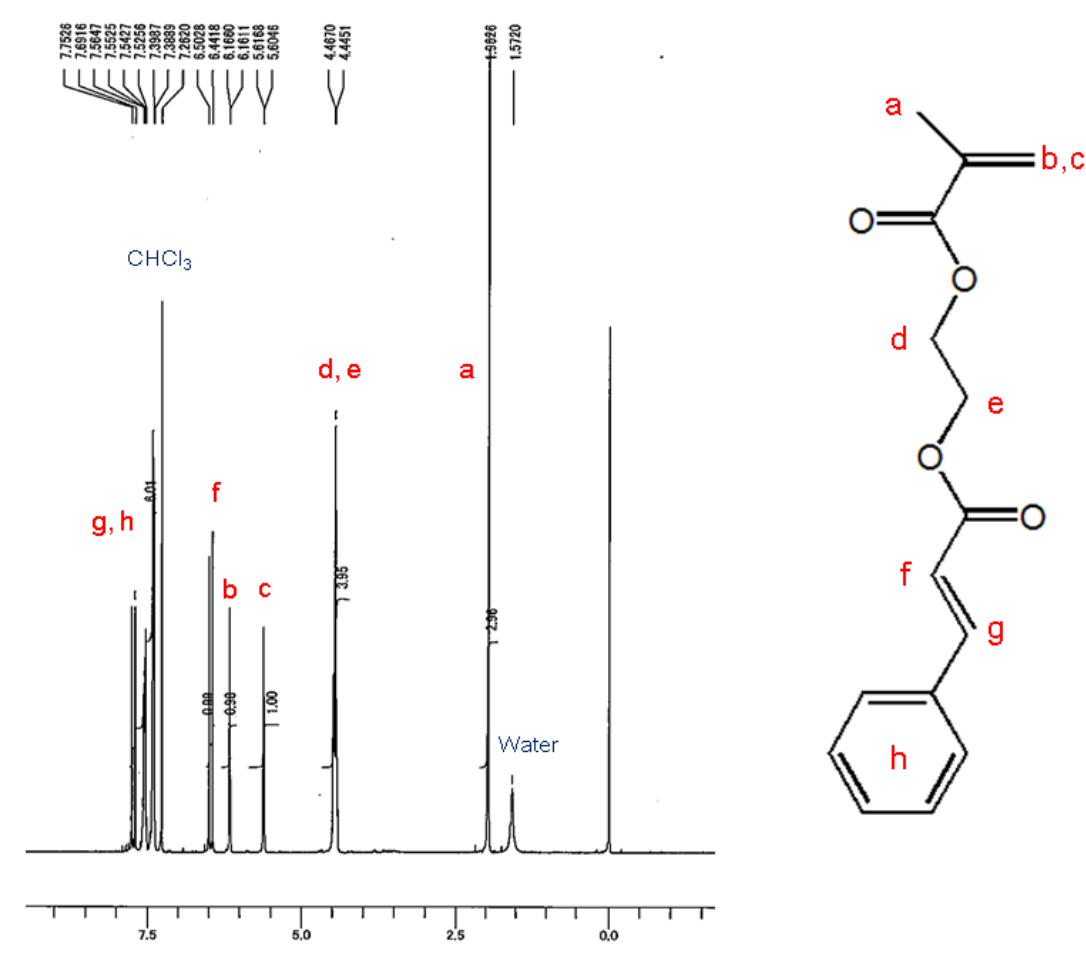

Figure S1 ${ }^{1} \mathrm{H}-\mathrm{NMR}$ spectrum of CEMA in $\mathrm{CDCl}_{3}$ 


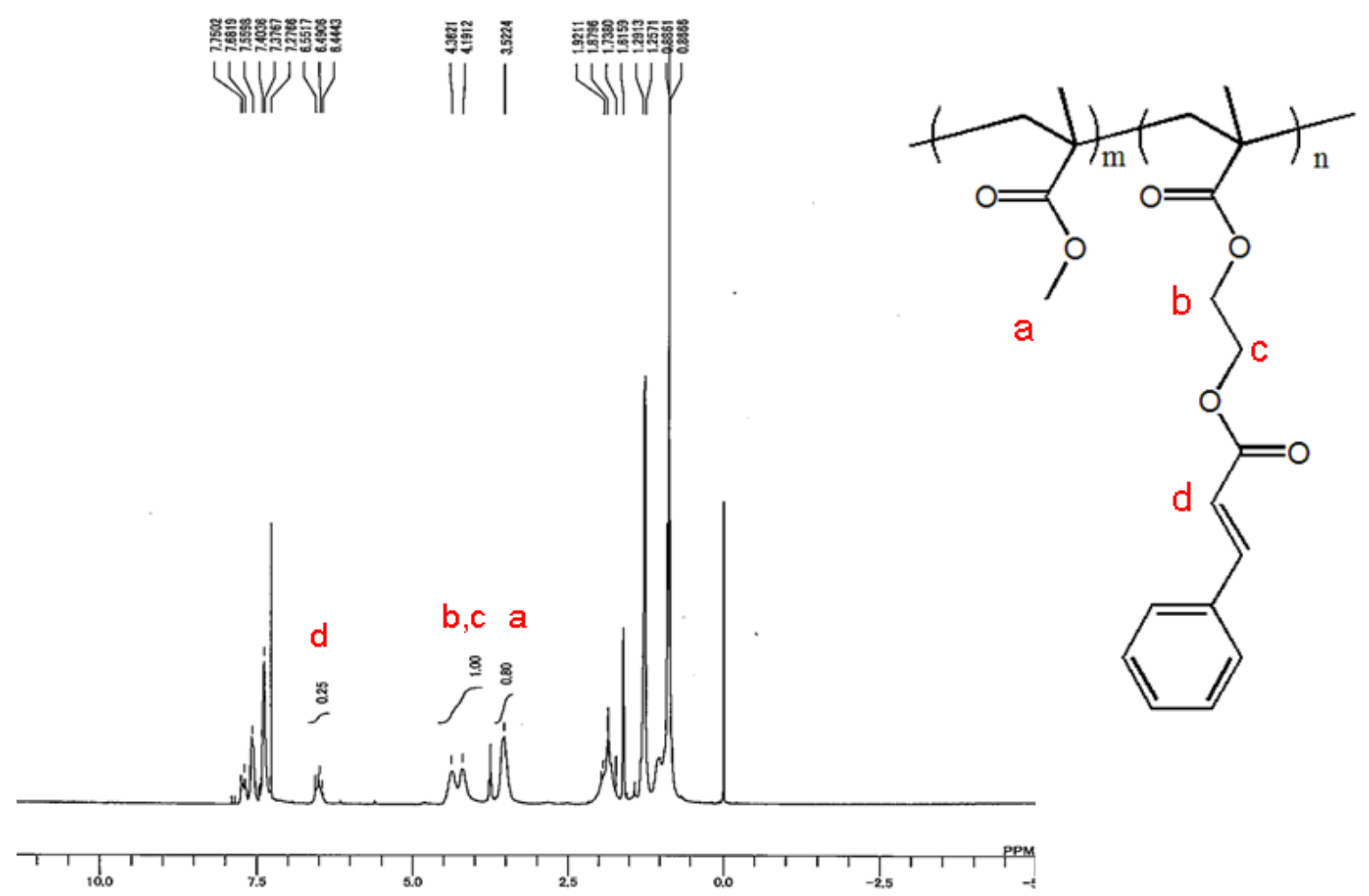

Figure $\mathrm{S} 2{ }^{1} \mathrm{H}-\mathrm{NMR}$ spectrum of $\mathrm{P}(\mathrm{CEMA}-\mathrm{MMA})-50$ in $\mathrm{CDCl}_{3}$

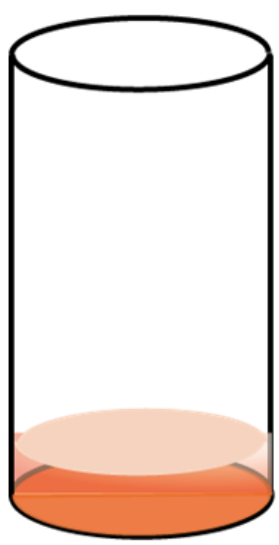

P(CEMA-MMA)-50 Toluene solution

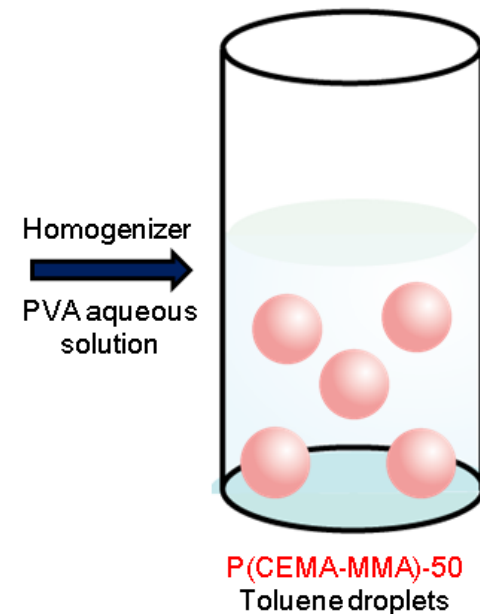

Toluenedroplets

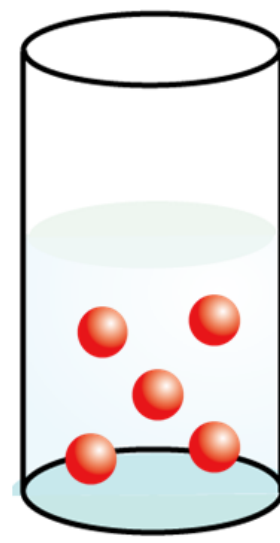

P(CEMA-MMA)-50 Particles

Scheme S1 Solvent evaporation method 

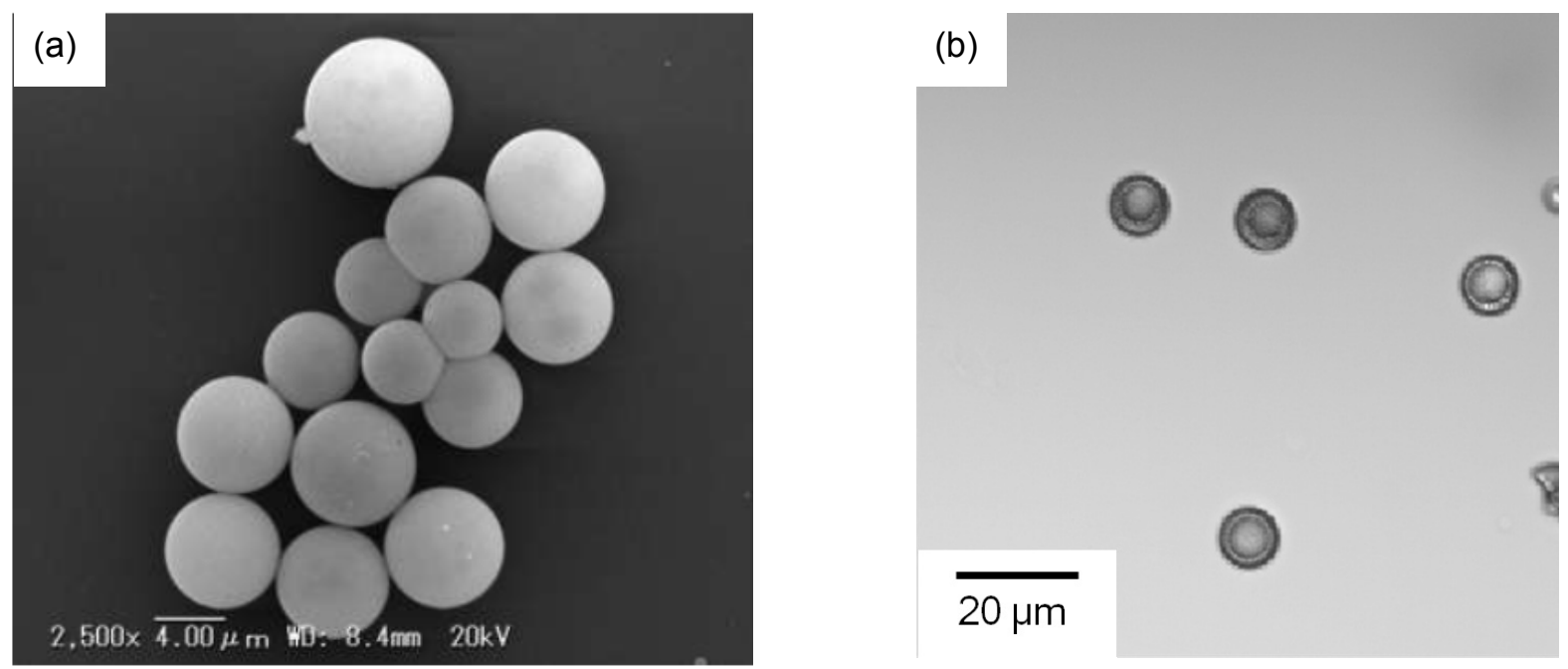

Figure S3 SEM (a) and optical micrograph (b) images of P(CEMA-MMA)-50 after photo-irradiation for $2 \mathrm{~h}$, followed by THF washing. The sample was re-dispersed in water after THF washing.

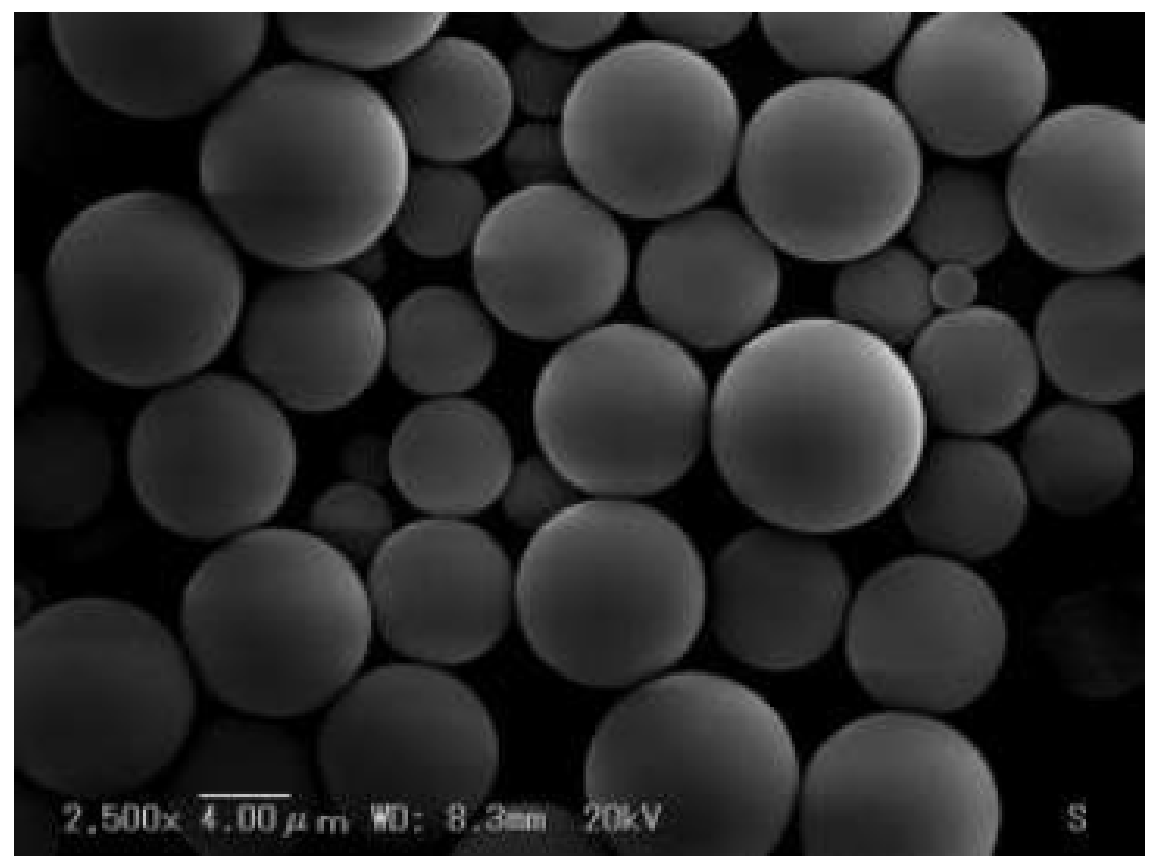

Figure S4 SEM image of P(CEMA-MMA-FAm)-50 after solvent evaporation method. 

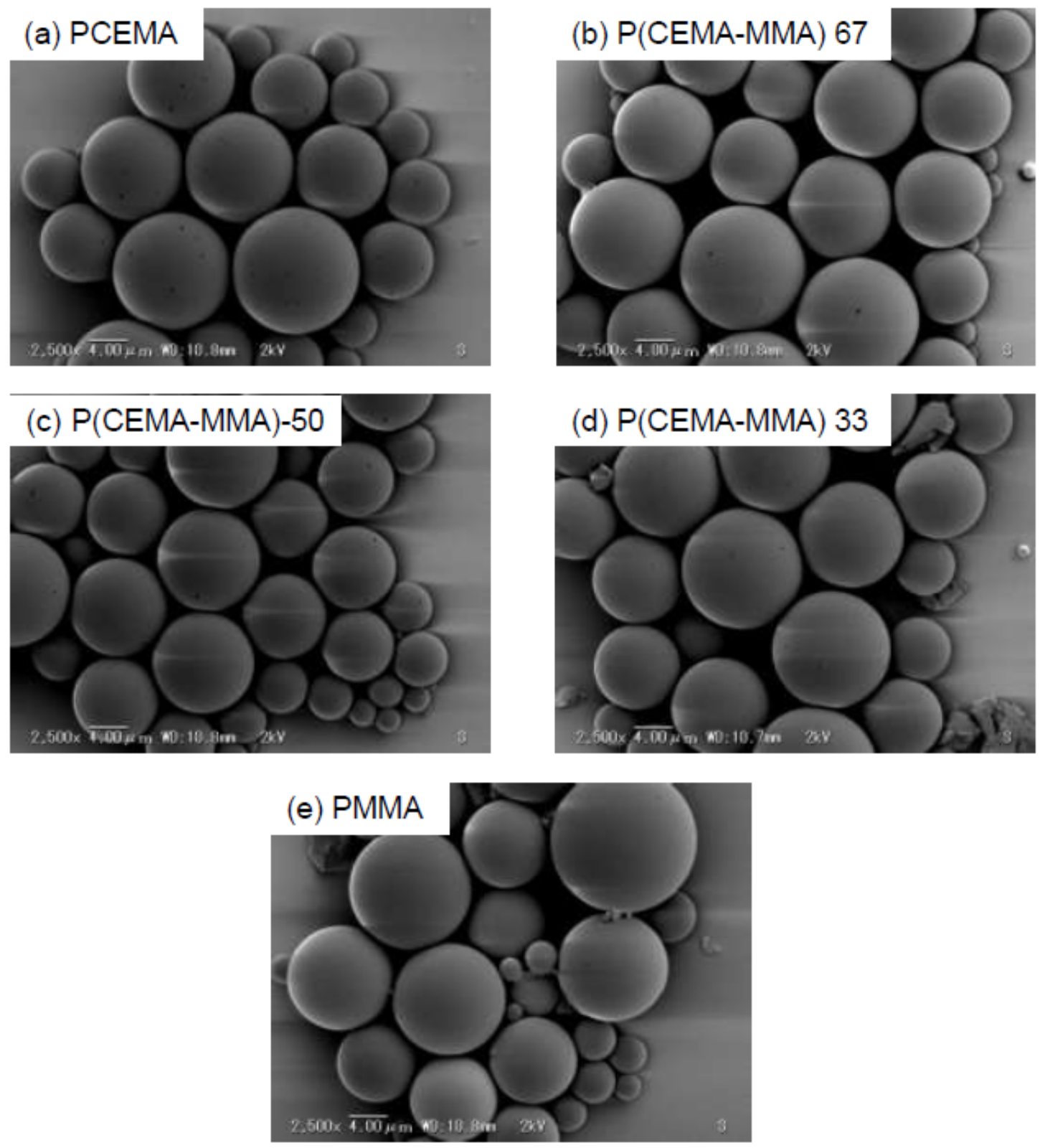

Figure S5 SEM images of P(CEMA) (a), P(CEMA-MMA)-67 (b), P(CEMA-MMA)-50 (c), P(CEMA-MMA)-33 (d), and PMMA (e) before photo-irradiation 


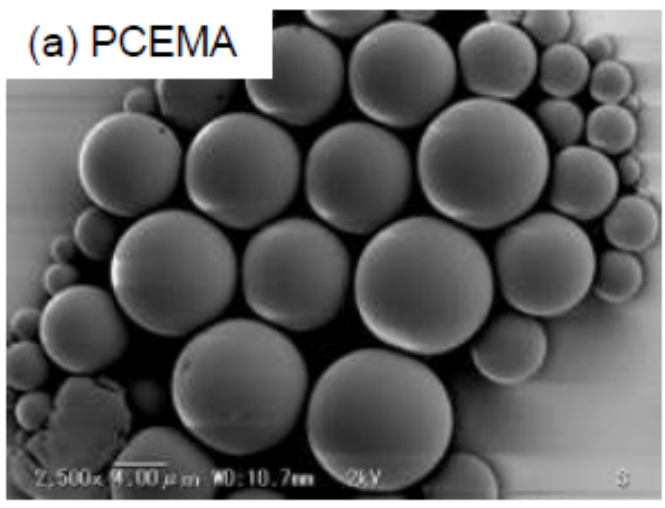

\section{(b) P(CEMA-MMA) 67}
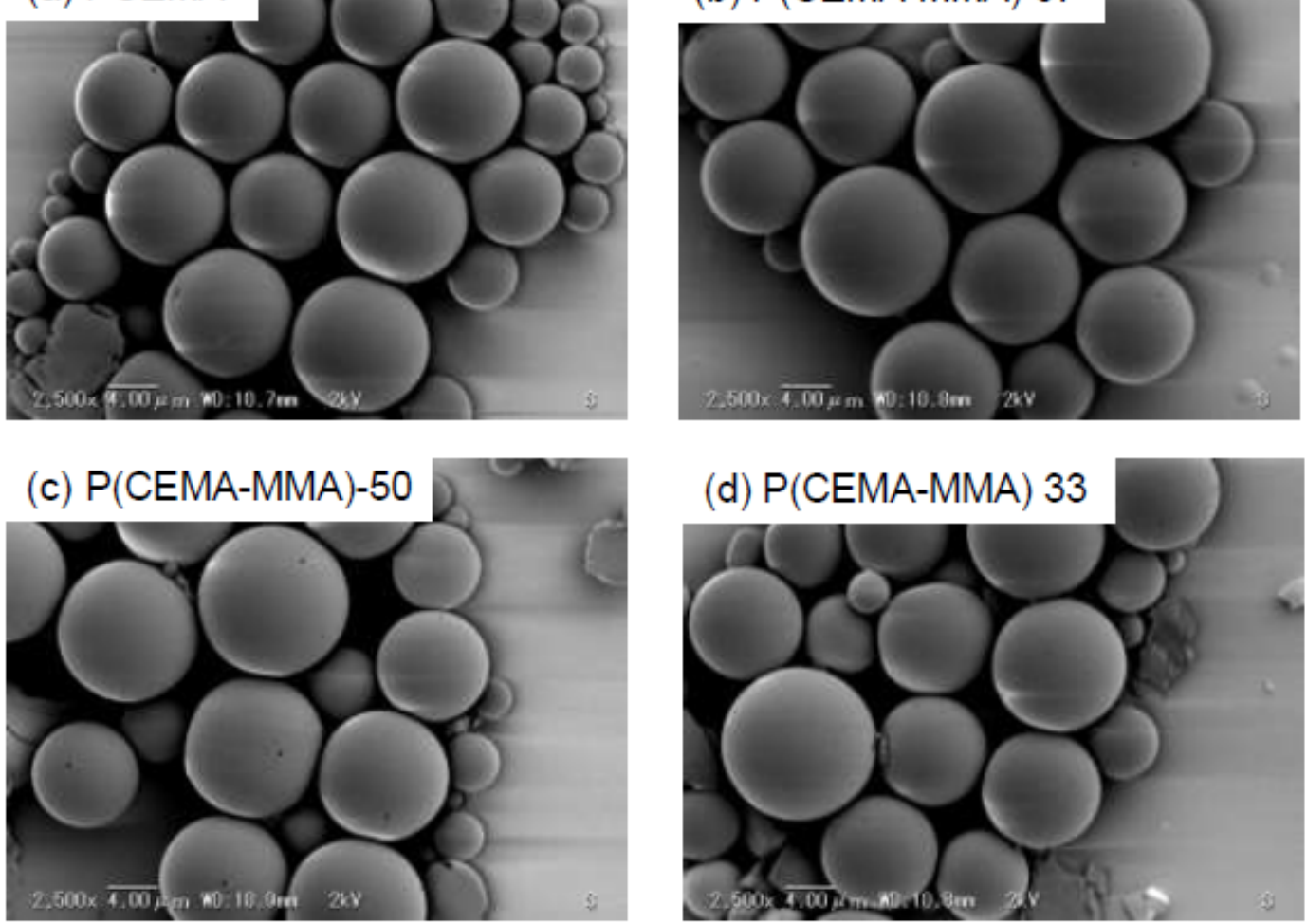

Figure S6 SEM images of P(CEMA) (a), P(CEMA-MMA)-67 (b), P(CEMA-MMA)-50 (c), and P(CEMA-MMA)-33 (d) after posteriori photo-induced cross-linking 


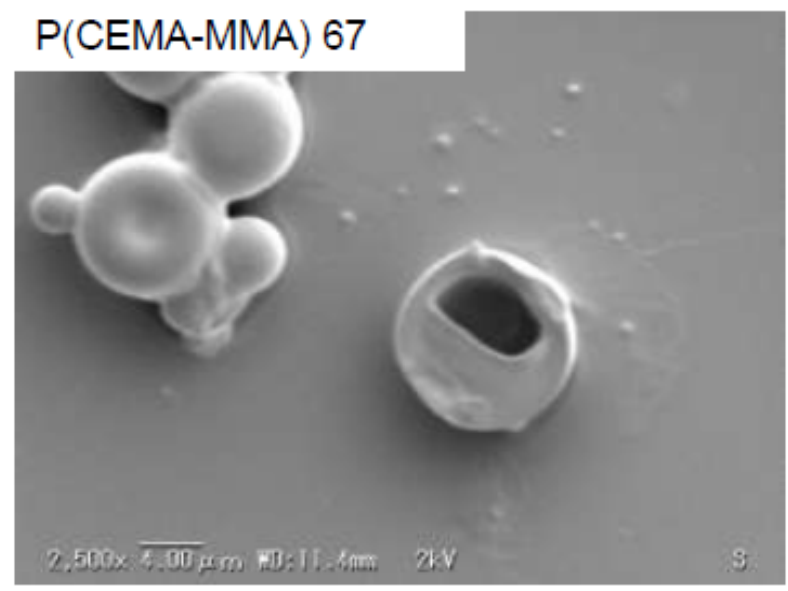

Figure S7 SEM image of accidentally broken P(CEMA-MMA)-67 after posteriori photo-induced cross-linking for $2 \mathrm{~h}$, followed by THF washing

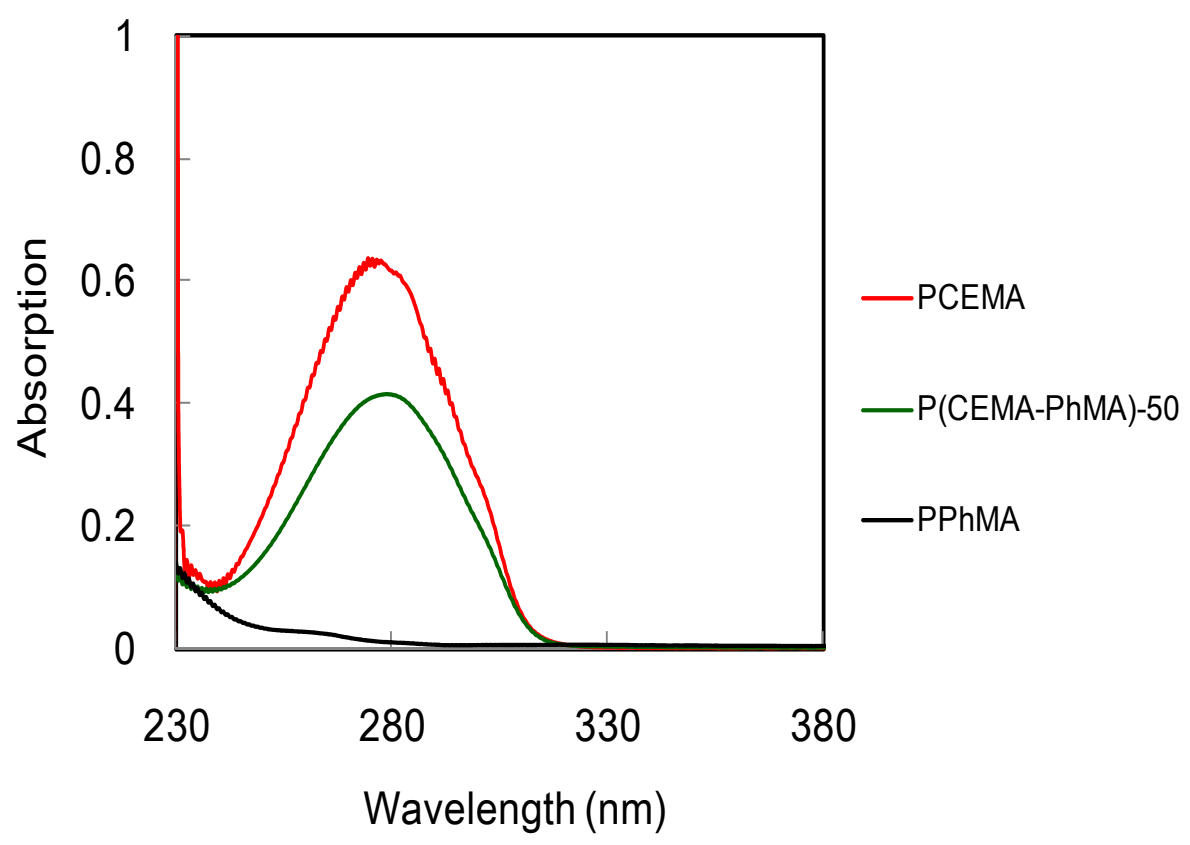

Figure S8 UV-Vis spectra of P(CEMA) (red), P(CEMA-PhMA)-50 (green), and PPhMA (black) dissolving in DCM $(10 \mu \mathrm{g} . / \mathrm{mL})$. 

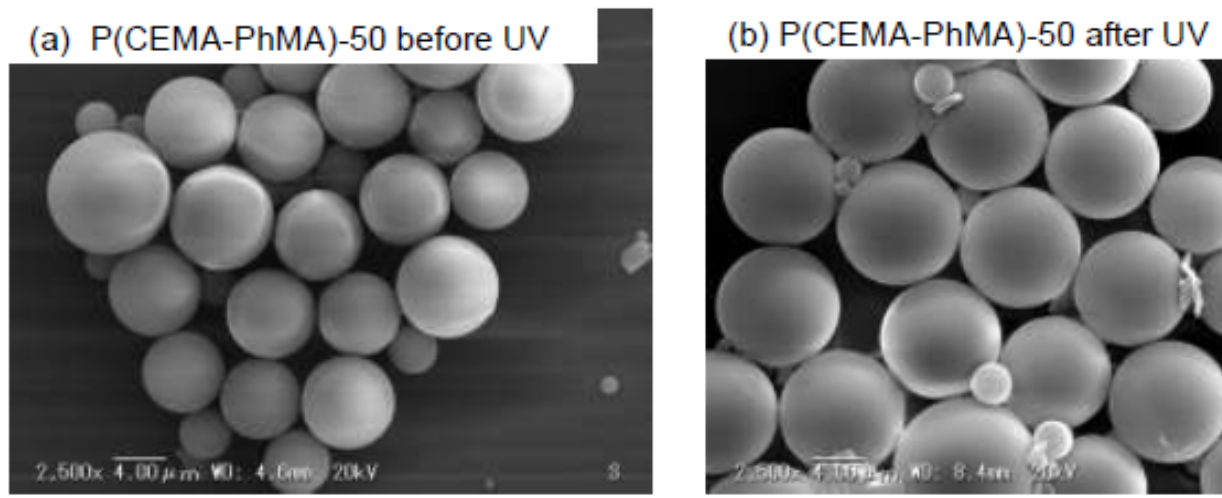

(c) P(CEMA-PhMA)-50 after THF

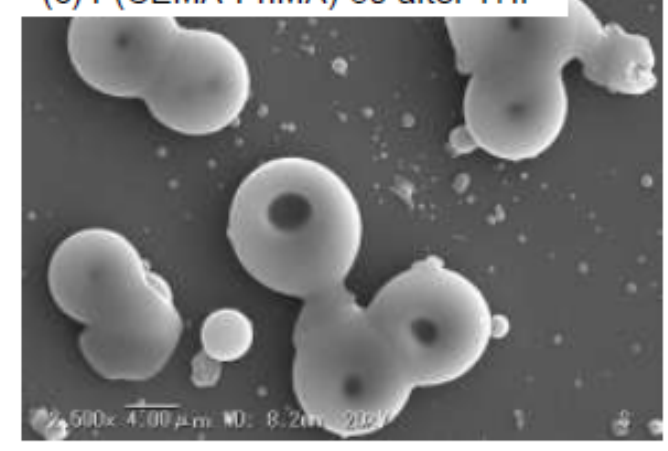

Figure S9 SEM images of P(CEMA-PhMA)-50 before posteriori photo-induced cross-linking (a), after photo-irradiation (b), and subsequent THF washing (c)

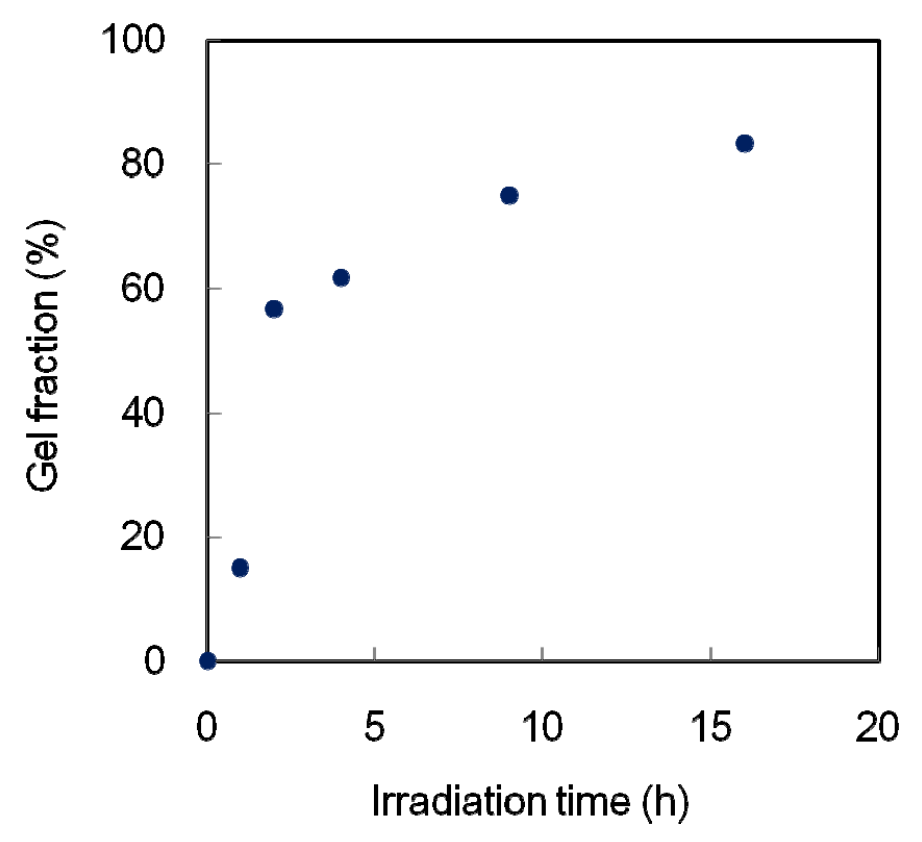

Figure S10 Time course of gel fraction of P(CEMA-PhMA). 


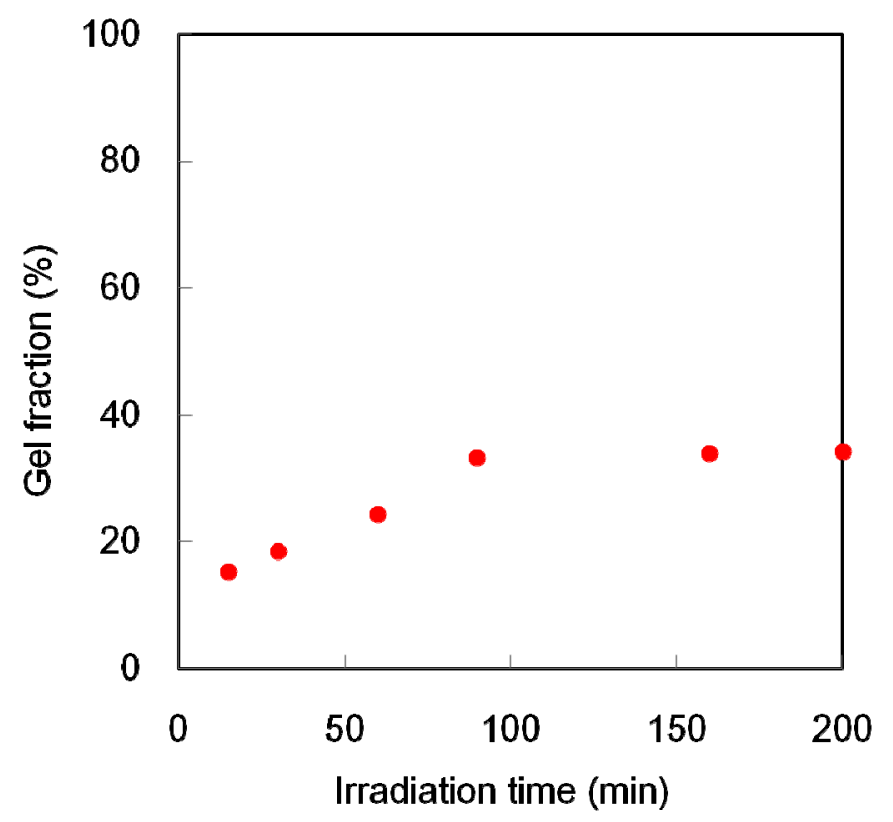

Figure S11 Gel fraction of P(CEMA-MMA)-50 films $(100 \mathrm{mg})$ at various photo-irradiation times on the glass petri dish (the area of base: $127 \mathrm{~cm}^{2}$ ), where the P(CEMA-MMA)-50.

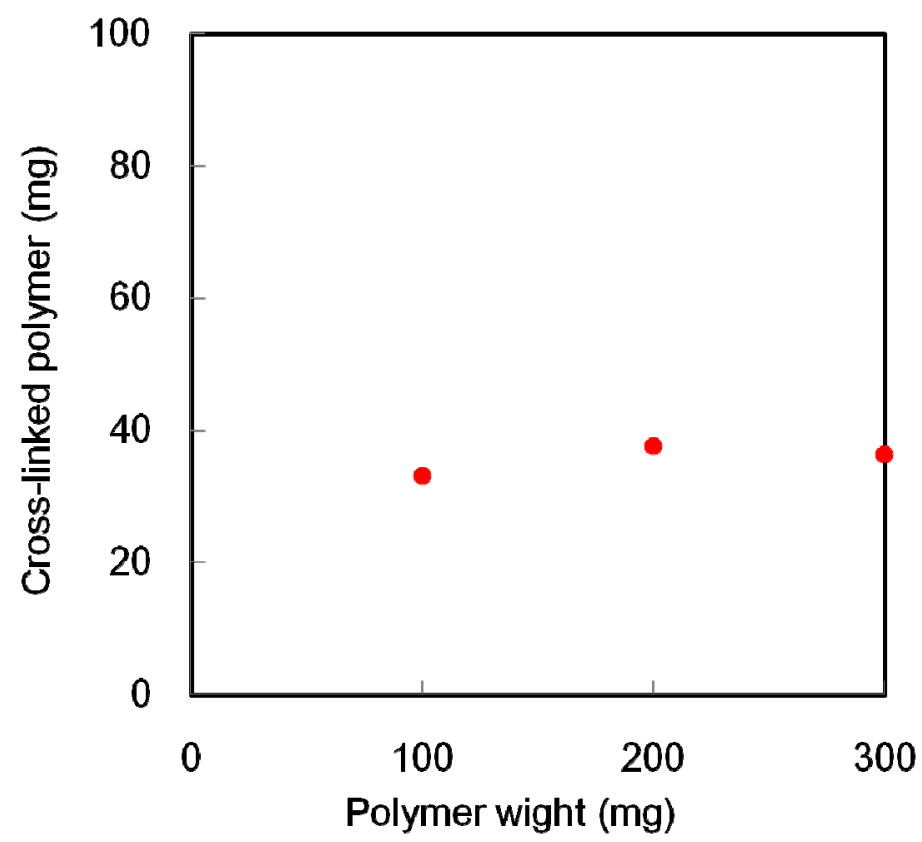

Figure S12 Gel fraction of P(CEMA-MMA)-50 films at $90 \mathrm{~min}$ on the glass petri dish (the area of base: $127 \mathrm{~cm}^{2}$ ) with different weight of polymer films (100 mg, $200 \mathrm{mg}$, and $300 \mathrm{mg}$ ), where the P(CEMA-MMA)-50. 


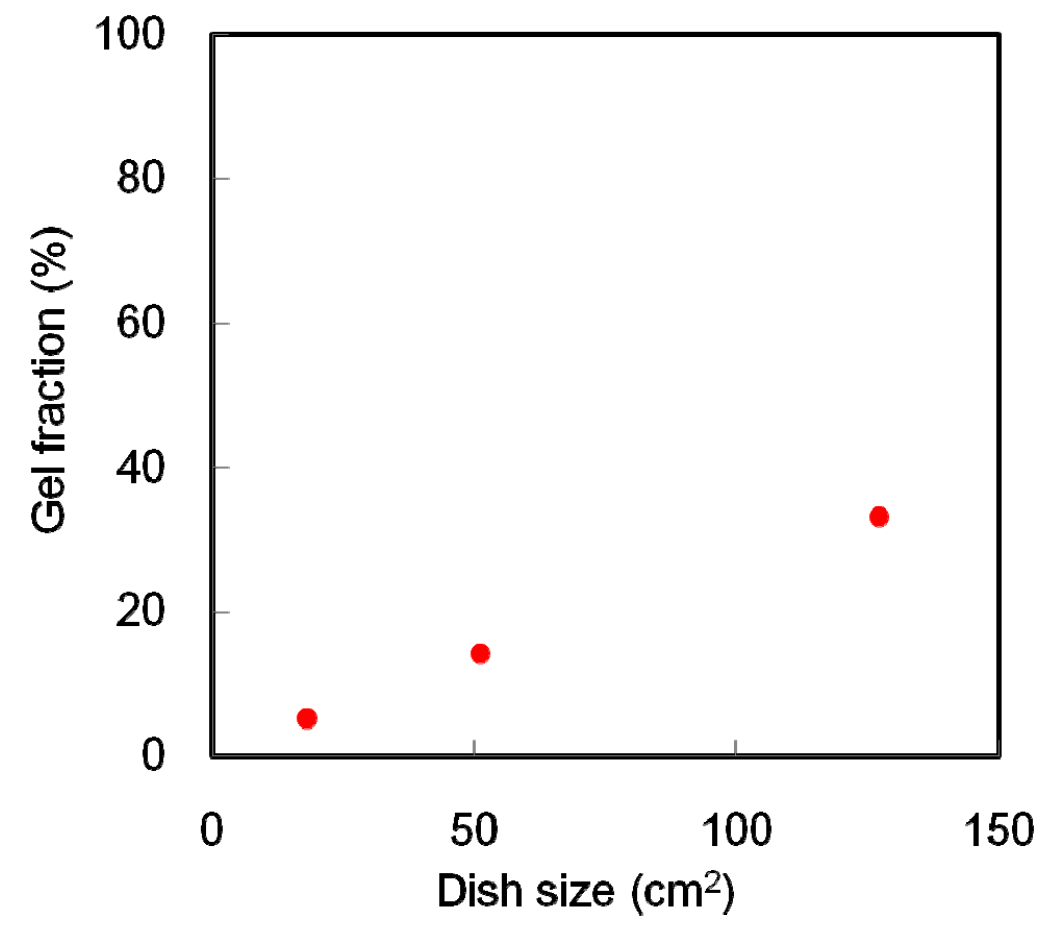

Figure S13 Gel fraction of $\mathrm{P}(\mathrm{CEMA}-\mathrm{MMA})-50$ films $(100 \mathrm{mg})$ at $90 \mathrm{~min}$ on the various glass petri dish bearing three different areas of the base $\left(18 \mathrm{~cm}^{2}, 51 \mathrm{~cm}^{2}\right.$, and $\left.127 \mathrm{~cm}^{2}\right)$, where the P(CEMA-MMA)-50. 